\title{
Therapeutic plasma exchange in heart transplantation: role of coagulation assessment with thromboelastometry
}

\author{
Andrew Crabbe', John S. McNeil ${ }^{2}$, Seema P. Deshpande ${ }^{1}$, Zachary Kon³ ${ }^{3}$ Si M. Pham³ and Kenichi A. Tanaka ${ }^{\text {1* }}$
}

\begin{abstract}
Therapeutic plasma exchange (TPE) is a potentially life-saving procedure which effectively removes donor-specific human leukocyte antigen (HLA) antibodies from the bloodstream, allowing critically ill heart transplant recipients to receive a donor organ with less wait time, and reducing the risk of acute organ rejection. The bulk of coagulation factors is initially removed from the blood during TPE using albumin and is later replaced with allogeneic plasma. Coagulopathy may develop during TPE and then can persist due to intraoperative blood loss and hemodilution during surgery and cardiopulmonary bypass. We hereby describe the utility of rotational thromboelastometry to assess rapid coagulation changes during TPE and subsequent heart transplant (HT) surgery.
\end{abstract}

Keywords: Coagulation, Plasma exchange, Fresh frozen plasma, Coagulation factor deficiency, Heart transplantation

\section{Background}

Therapeutic plasma exchange (TPE) is a procedure that is used to remove potentially harmful antibodies and toxins from a patient. It is indicated for many disease conditions including autoimmune anemia, autoimmune vasculitis, hemolytic uremic syndrome, and multiple sclerosis [1]. TPE has been used in perioperative cardiac surgical patients with antibodies relating to heparininduced thrombocytopenia [2], ABO incompatibility [3], and donor-specific human leukocyte antigen (HLA) [4]. The latter antibodies (ABO and HLA) are pertinent to organ donor matching, and transplant recipients may suffer from long waits for organs due to incompatible antibodies. Perioperative removal of these antibodies via TPE is feasible and often life-saving for critically ill organ recipients.

Albumin (5\%) is useful as an exchange fluid for serial TPEs because of potential risks associated with a large amount of fresh frozen plasma (hereinafter referred to as plasma) [5]. In particular, allergic reactions can occur in up to $40-65 \%$ of patients undergoing multiple TPEs, although the severity of symptoms may vary [5-7]. It is

\footnotetext{
* Correspondence: ktanaka@anes.umm.edu

${ }^{1}$ Department of Anesthesiology, University of Maryland, 22 South Greene

Street, Suite S8D12, Baltimore, MD 21201, USA

Full list of author information is available at the end of the article
}

thus routine at our institution to perform two plasma volume exchanges using $5 \%$ albumin, followed by another TPE with plasma. The loss of coagulation factors during TPE is expected [8], but there is no strong evidence to support the superiority of plasma-only TPE over albumin/plasma combination for non-surgical TPE indications [5, 9]. Perioperative TPEs using albumin/plasma raise concerns about coagulation status because a single TPE with plasma may be insufficient to fully restore hemostatic factor levels before the use of cardiopulmonary bypass (CPB). Rotational thromboelastometry (TEM Innovations, Munich) was thus used to assess rapid coagulation changes during repeat TPEs in this case of a patient with donor-specific HLA antibodies who underwent a heart transplantation. The aim of this report is to address the clinical implications of TPE on coagulation and hemodynamic management in the transplant recipient.

\section{Case presentation}

A 43-year-old female, $66 \mathrm{~kg}$, with non-ischemic cardiomyopathy (NICM) presented for HT. She was diagnosed with NICM 15 years ago, presumably related to pregnancy and/or systemic lupus erythematous (SLE). Her past medical history included SLE with associated nephritis and vasculitis, insulin-dependent diabetes mellitus, 
previous pulmonary embolism, and previous stroke with residual visual field defects.

The patient had been stable on a biventricular assist device (BiVAD; HeartWare, Framingham, MA, USA) for 2 years while no HLA-matched donor was found despite a $1 \mathrm{~b}$ (moderate urgency) status. She was recently hospitalized for worsening right heart function and was requiring increased inotropic support. Given the decline in her clinical condition, the transplant team decided to use therapeutic plasma exchange (TPE), anti-lymphocyte antibody treatment, and intravenous immunoglobulin treatment in the perioperative period in order to accept a cross-match positive donor heart $[4,10]$.

After an uneventful induction of anesthesia and line placement, a large dual lumen catheter was placed in the femoral vein and connected to the plasmapheresis device (Prismaflex ${ }^{\circ}$ System, GAMBRO, Colorado). She underwent TPEs consisting of three plasma volume exchanges; the first two exchanges used $5 \%$ albumin $(3300 \mathrm{ml}$ each) to remove the HLA antibodies. The third plasma exchange utilized 11 units of FFP to restore coagulation factors for surgery. Throughout the procedure, coagulation status was assessed using tissue factor-activated EXTEM and FIBTEM on rotational thromboelastometry (Fig. 1). Baseline (pre-TPE) EXTEM and FIBTEM parameters were within normal range except for a high FIBTEM-A $A_{10}$. After TPE with albumin, EXTEM-CT increased from 55 to $74 \mathrm{~s}$. FIBTEM-A $\mathrm{A}_{10}$ decreased from 34 to $9 \mathrm{~mm}(-64.0 \%)$ (Fig. 1a, b). TPE continued with FFP $(\sim 35 \mathrm{ml} / \mathrm{kg})$ during the explantation of the BiVAD device, and FIBTEM- $\mathrm{A}_{10}$ was $7 \mathrm{~mm}$ at the conclusion of this third round of TPE (Fig. 1c). Measured plasma fibrinogen levels, which were reported approximately 25-45 $\mathrm{min}$ after FIBTEM- $\mathrm{A}_{10}$ results were available, confirmed a net loss of fibrinogen (Fig. 1a, c).

The donor heart was implanted over $192 \mathrm{~min}$ of CPB with a cross-clamp time of $93 \mathrm{~min}$ and a donor ischemic time of $256 \mathrm{~min}$. After transplant and reperfusion, the patient was initially weaned from $\mathrm{CPB}$ with inotropic support (epinephrine $0.06 \mu \mathrm{g} / \mathrm{kg} / \mathrm{min}$ and norepinephrine $0.03 \mu \mathrm{g} / \mathrm{kg} / \mathrm{min}$ ). Diffuse microvascular bleeding was attributed to thrombocytopenia (EXTEM- $\mathrm{A}_{10}, 31 \mathrm{~mm}$ ) and low fibrinogen (FIBTEM-A $10,7 \mathrm{~mm}$ ) (Fig. 1c). One pool of five single donor platelets and 20 units (four pools) of cryoprecipitate were transfused, and improved hemostasis was observed in the surgical field in conjunction with normalized EXTEM and FIBTEM $\mathrm{A}_{10}$ values (Fig. 1d).

In the post-CPB period, systolic dysfunction persisted on increasing doses of epinephrine and norepinephrine (up to $0.1 \mu \mathrm{g} / \mathrm{kg} / \mathrm{min}$ ) despite adding vasopressin (0.06 units $/ \mathrm{min})$ and milrinone $(0.375 \mu \mathrm{g} / \mathrm{kg} / \mathrm{min})$. Levothyroxine $\left(\mathrm{T}_{4} ; 20 \mu \mathrm{g} / \mathrm{kg}\right.$ bolus, followed by $5 \mu \mathrm{g} /$ $\mathrm{kg} / \mathrm{h}$ infusion) was added to treat "stunned" myocardium due to the long ischemic time as well as the potential for "euthyroid sick syndrome" exacerbated by TPE $[11,12]$.

The transplant heart's systolic function improved with the $\mathrm{T}_{4}$ infusion, and further mechanical support (e.g., veno-arterial extracorporeal membrane oxygenation) was avoided. The patient remained stable in the intensive care unit (ICU), and the $\mathrm{T}_{4}$ infusion was weaned off along with other inotropes on postoperative day (POD) 2. In the ICU, four more sessions of TPE were performed to sustain the eradication of donor-specific antibodies; one plasma volume exchange with FFP on POD 1 and 2, and one plasma volume exchanged with $5 \%$ albumin on POD 3 and 5 (plasma fibrinogen levels were above $150 \mathrm{mg} / \mathrm{dL}$ after TPEs). The patient was extubated on POD 5 and discharged from the hospital on POD 14.

\section{Discussion}

Rotational thromboelastometry is a practical method to assess rapid coagulation changes during surgery and $\mathrm{CPB}$, and in this case report, it was used successfully during multiple TPEs for heart transplantation (HT). [13]. Tissue factor-activated tests, EXTEM and FIBTEM (Table 1), are most useful in the acute setting because extrinsic coagulation factors and fibrinogen, respectively, are particularly prone to hemodilution and blood (plasma) losses [14, 15]. Clotting time (CT) of EXTEM reflects prothrombin time (PT) sensitive coagulation factor levels [15], whereas 10 min amplitude $\left(\mathrm{A}_{10}\right.$ clot firmness) reflects platelet count and fibrinogen level [16]. FIBTEM better reflects plasma fibrinogen levels than EXTEM because its clot formation is fibrin specific due to the inclusion of cytochalasin $\mathrm{D}$, a platelet inhibitor, in the reagent $[16,17]$.

TPE is an important intervention for a variety of diseases that require the removal of undesirable toxins or antibodies. TPE potentially expands the donor pool for heart and lung transplants which otherwise can be limited by recipient antibodies to donor HLA. One to one and a half plasma volume runs of TPE generally remove 63-78\% of alloantibodies (mostly IgG class), and three TPEs can reduce these antibodies by $90 \%$ [18]. In conjunction with immunosuppressive agents, TPE can significantly reduce the risk of both acute and chronic allograft organ rejection [4]. Reduced FIBTEM values correlate with the substantial removal of large plasma proteins (IgG, $150 \mathrm{kDa}$, and fibrinogen, $340 \mathrm{kDa}$ ) at the end of albumin TPE [8]. Loss of fibrinogen and other coagulation proteins during albumin TPE increase the risk of bleeding, particularly after $\mathrm{CPB}$, and thus allogeneic plasma is generally recommended for intraoperative TPEs [2]. However, full recovery of fibrinogen is unlikely even if plasma-only TPE is used [5,9], and CPB-induced hemodilution further decreases plasma fibrinogen [17]. Post-CPB fibrinogen levels below $200 \mathrm{mg} / \mathrm{dL}$ 


\section{A Baseline}

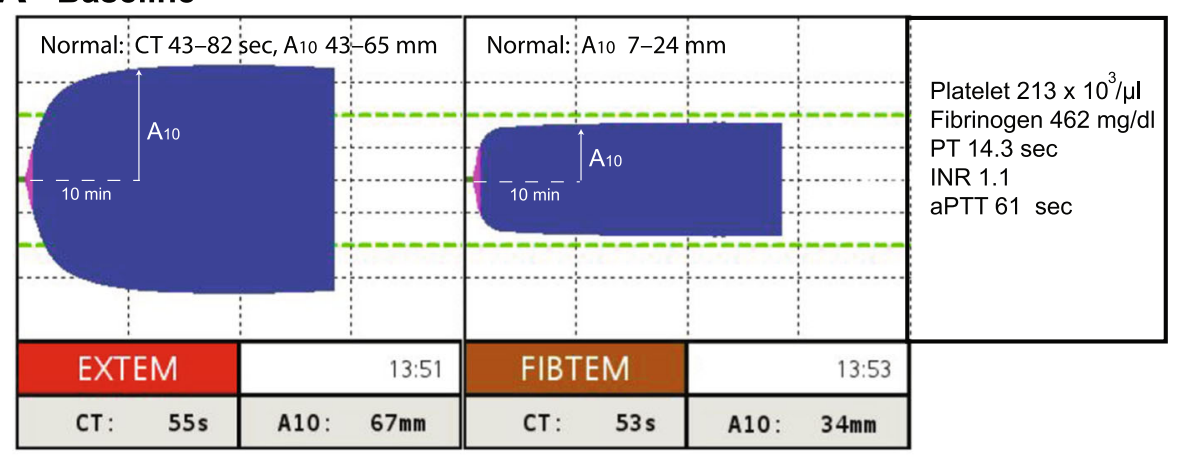

\section{B Post TPE with 5\% Albumin}

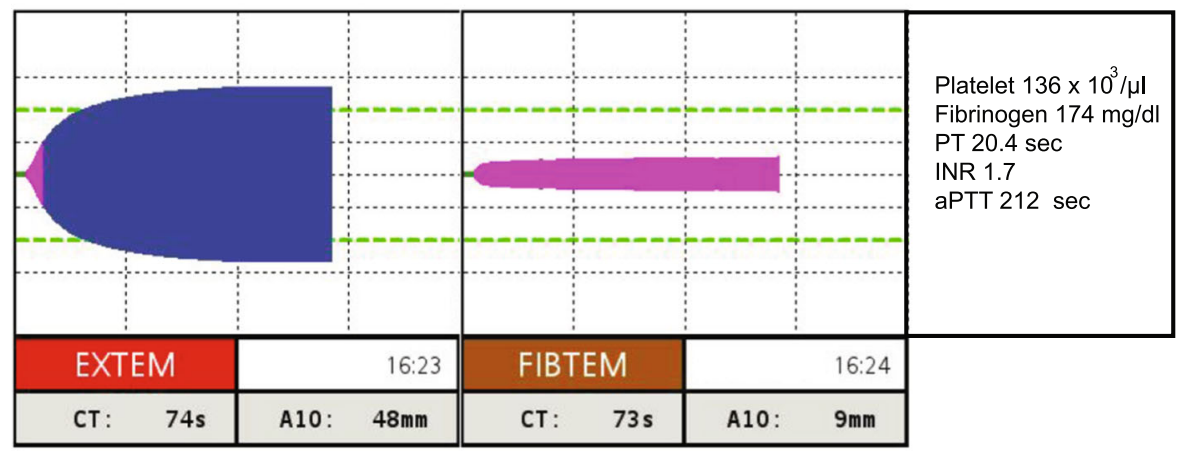

\section{Post TPE with Plasma during Transplant}

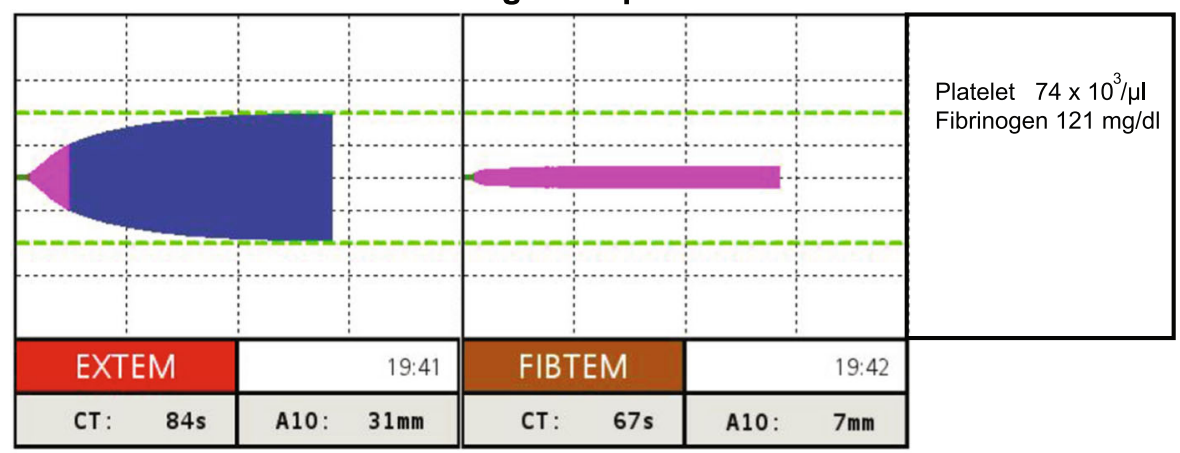

\section{End of Surgery}

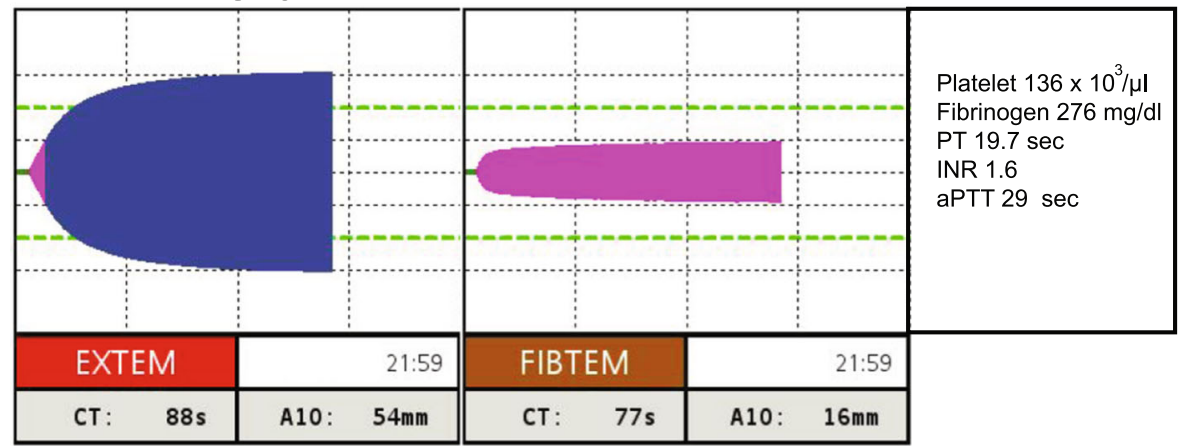

Fig. 1 a Key parameters of EXTEM-CT: clotting time (s) [normal, 43-82 s], EXTEM-A 110 : 10 min amplitude (mm) [normal, 43-65 mm], and FIBTEM-A 10 [normal, 9-24 mm]. b-d EXTEM and FIBTEM changes during and after therapeutic plasma exchange (TPE). Baseline fibrinogen was in supra-normal range (b), but it extensively decreased after TPE with albumin (c) and even after plasma replacement during surgery. Fibrinogen was restored only after the transfusion of cryoprecipitate (d) 
Table 1 Types of assays on rotational thromboelastometry

\begin{tabular}{|c|c|c|c|c|c|}
\hline Test & TF & Contact & Heparin effect & Detectable condition(s) & Hemostatic interventions \\
\hline EXTEM & + & & $-{ }^{a}$ & Extrinsic pathway, PLT count, fibrinolysis & Plasma, PCC, or PLTs \\
\hline FIBTEM & + & & $-{ }^{a}$ & Fibrinogen level $^{b}$ & Cryo or fibrinogen conc. \\
\hline APTEM & + & & $-{ }^{a}$ & Systemic fibrinolysis ${ }^{c}$ & Antifibrinolytics \\
\hline INTEM & & + & + & Intrinsic pathway, PLT count, fibrinolysis & Plasma, protamine, or PLTs \\
\hline HEPTEM & & + & $-^{\mathrm{a}}$ & Heparin effect & Same as INTEM \\
\hline
\end{tabular}

ACT activated clotting time, Cryo cryoprecipitate, Fibrinogen conc. fibrinogen concentrate, PCC prothrombin complex concentrate, $P L T$ platelet, $T F$ tissue factor activator, Contact contact activator (ellagic acid)

${ }^{a}$ Heparin is neutralized by the reagent at concentrations up to $4-6 \mathrm{U} / \mathrm{ml}$ on EXTEM/FIBTEM/APTEM and $8 \mathrm{U} / \mathrm{ml}$ on HEPTEM

${ }^{b}$ Confirmatory test for hypofibrinogenemia; low clot firmness (amplitude) on other ROTEM ${ }^{\star}$ tests may indicate either thrombocytopenia or hypofibrinogenemia

${ }^{c}$ Confirmatory test for fibrinolysis; fibrinolysis may be shown on all the other ROTEM ${ }^{\circledR}$ tests

(FIBTEM- $\mathrm{A}_{10}<10 \mathrm{~mm}$ ) are associated with an increased risk of bleeding and higher transfusion requirement $[19,20]$, and the restoration of fibrinogen to $>250 \mathrm{mg} / \mathrm{dL}$ (FIBTEM-A $10>15-18 \mathrm{~mm}$ ) appears to reduce such risks [21]. We initially calculated the required amount $(\mathrm{g})$ of fibrinogen using the published formula below based on the FIBTEM-A $A_{10}$ value [21-23]:

$$
\text { Fibrinogen } \begin{aligned}
(\mathrm{g}) & =\left[\text { target FIBTEM- } \mathrm{A}_{10}(\mathrm{~mm})-\text { current FIBTEM- } \mathrm{A}_{10}(\mathrm{~mm})\right] \\
& \times \text { weight }(\mathrm{kg}) \div 140=(15 \mathrm{~mm}-7 \mathrm{~mm}) \\
& \times 66 \mathrm{~kg} \div 140=3.77 \mathrm{~g}
\end{aligned}
$$

In the USA, clinical use of fibrinogen concentrate is limited to hereditary afibrinogenemia and hypofibrinogenemia [24], and thus cryoprecipitate remains the mainstay therapy for perioperative fibrinogen replacement. The required amount (units) of cryoprecipitate can be estimated by multiplying the fibrinogen dose by five [25]; $3.77 \times 5=18.9$ units.

After transfusing 20 units of cryoprecipitate, FIBTEM$\mathrm{A}_{10}$ and fibrinogen were $16 \mathrm{~mm}$ and $276 \mathrm{mg} / \mathrm{dL}$, respectively.

Our case demonstrates the practical use of EXTEM and FIBTEM in monitoring perioperative changes in fibrinogen levels and the therapeutic effects of cryoprecipitate (Fig. 1c, d) during TPE. It is also important to note that antibiotics (ceftazidime, tobramycin, etc.) and immunosuppressants (basiliximab) can also be eliminated by TPE $[26,27]$.

In addition, TPE is known to affect biologically active hormones, including free thyroxine $\left(\mathrm{T}_{4}\right)$ and triiodothyronine $\left(\mathrm{T}_{3}\right)$ [12]. Critically ill patients have limited reserves of thyroid hormones [11], and there is some evidence to suggest that there is better preservation and function of the donor heart using $\mathrm{T}_{3}$ or $\mathrm{T}_{4}$ infusion [28]. Therefore, $\mathrm{T}_{4}$ infusion may be potentially useful for the management of stunned donor heart.

\section{Conclusions}

In conclusion, the use of TPE expands the donor organ pool to patients who otherwise would have an either a low probability of or a long wait before receiving a donor organ. In these patients, thromboelastometry throughout the perioperative period can allow for a fast detection of coagulopathy and targeted component therapy $[25,29]$.

Funding

None.

Authors' contributions

AC: This author managed the patient, collected the data, and wrote the manuscript. JM, SD, ZK, SP: These authors contributed to the patient care, and helped write the manuscript.KT: This author managed the patient, and helped write the manuscript. All authors read and approved the final manuscript.

\section{Competing interests}

Kenichi A. Tanaka is currently participating in a clinical study sponsored by TEM Innovations (Munich, Germany). All other authors declare that they have no competing interests.

\section{Consent for publication}

Written informed consent was obtained from the patient for the publication of this report.

\section{Author details}

${ }^{1}$ Department of Anesthesiology, University of Maryland, 22 South Greene Street, Suite S8D12, Baltimore, MD 21201, USA. ²Department of Anesthesiology, University of Virginia, Charlottesville, VA, USA. ${ }^{3}$ Department of Surgery, Division of Cardiothoracic Surgery, University of Maryland, Baltimore, MD, USA

Received: 8 June 2016 Accepted: 11 October 2016

Published online: 19 October 2016

\section{References}

1. Winters JL. Plasma exchange: concepts, mechanisms, and an overview of the American Society for Apheresis guidelines. Hematology. 2012;2012:7-12.

2. Roman PE, DeVore AD, Welsby IJ. Techniques and applications of perioperative therapeutic plasma exchange. Current Opin Anaesthesiol. 2014;27:57-64.

3. Issitt RW, Crook RM, Cross NT, Shaw M, Robertson A, Burch M, Hsia TY, Tsang VT. Incompatible ABO-plasma exchange and its impact on patient selection in paediatric cardiac transplantation. Perfusion. 2012;27:480-5.

4. Tinckam KJ, Keshavjee S, Chaparro C, Barth D, Azad S, Binnie M, Chow CW, de Perrot M, Pierre AF, Waddell TK, Yasufuku K, Cypel M, Singer LG. Survival in sensitized lung transplant recipients with perioperative desensitization. Am J Transplant. 2015:15:417-26.

5. O'Brien $\mathrm{KL}$, Price $\mathrm{TH}$, Howell C, Delaney M. The use of $50 \%$ albumin/plasma replacement fluid in therapeutic plasma exchange for thrombotic thrombocytopenic purpura. J Clin Apher. 2013;28:416-21. 
6. Bell WR, Braine HG, Ness PM, Kickler TS. Improved survival in thrombotic thrombocytopenic purpura-hemolytic uremic syndrome. Clinical experience in 108 patients. New Engl J Med. 1991;325:398-403.

7. Reutter JC, Sanders KF, Brecher ME, Jones HG, Bandarenko N. Incidence of allergic reactions with fresh frozen plasma or cryo-supernatant plasma in the treatment of thrombotic thrombocytopenic purpura. J Clin Apher. 2001; 16:134-8.

8. Hanafusa N, Satonaka H, Doi K, Noiri E, Fujita T. Virus removal and eradication by modified double filtration plasmapheresis decreases factor XIII levels. Ther Apher Dial. 2010;14:287-91.

9. Brecher ME, Hay SN, Park YA. Theoretical efficacy of using albumin/plasma versus full plasma replacement in TTP. J Clin Apher. 2011;26:58.

10. Ballew CC, Bergin JD. Management of patients with preformed reactive antibodies who are awaiting cardiac transplantation. Am J Crit Care. 2005; 14:46-51.

11. Novitzky D, Cooper DK. Thyroid hormone and the stunned myocardium. J Endocrinol. 2014;223:R1-8.

12. Muller C, Perrin P, Faller B, Richter $S$, Chantrel F. Role of plasma exchange in the thyroid storm. Ther Apher Dial. 2011;15:522-31.

13. Weber CF, Gorlinger K, Meininger D, Herrmann E, Bingold T, Moritz A, Cohn LH, Zacharowski K. Point-of-care testing: a prospective, randomized clinical trial of efficacy in coagulopathic cardiac surgery patients. Anesthesiology. 2012;117:531-47.

14. Yuan S, Ferrell C, Chandler WL. Comparing the prothrombin time INR versus the APTT to evaluate the coagulopathy of acute trauma. Thromb Res. 2007; 120:29-37.

15. Abuelkasem E, Mazzeffi MA, Lu SY, Planinsic RM, Sakai T, Tanaka KA. Ex vivo evaluation of 4 different viscoelastic assays for detecting moderate to severe coagulopathy during liver transplantation. Liver Transplant. 2016;22:468-75.

16. Olde Engberink RH, Kuiper GJ, Wetzels RJ, Nelemans PJ, Lance MD, Beckers EA, Henskens YM. Rapid and correct prediction of thrombocytopenia and hypofibrinogenemia with rotational thromboelastometry in cardiac surgery. J Cardiothorac Vasc Anesth. 2014;28:210-6.

17. Ogawa S, Szlam F, Bolliger D, Nishimura T, Chen EP, Tanaka KA. The impact of hematocrit on fibrin clot formation assessed by rotational thromboelastometry. Anesth Analg. 2012;115:16-21.

18. Rummler S, Barz D. Plasma exchange and immunoadsorption of patients with thoracic organ transplantation. Transfus Med Hemother. 2012;39:234-40

19. Bolliger D, Gonsahn M, Levy JH, Williams WH, Tanaka KA. Is preoperative fibrinogen predictive for postoperative bleeding after coronary artery bypass grafting surgery? Transfusion. 2009:49:2006-7.

20. Karkouti K, Callum J, Crowther MA, McCluskey SA, Pendergrast J, Tait G, Yau TM, Beattie WS. The relationship between fibrinogen levels after cardiopulmonary bypass and large volume red cell transfusion in cardiac surgery: an observational study. Anesth Analg. 2013;117:14-22.

21. Ranucci M, Baryshnikova E, Crapelli GB, Rahe-Meyer N, Menicanti L, Frigiola A, Surgical Clinical Outcome RG. Randomized, double-blinded, placebocontrolled trial of fibrinogen concentrate supplementation after complex cardiac surgery. J Am Heart Assoc. 2015;4:e002066.

22. Solomon C, Pichlmaier U, Schoechl H, Hagl C, Raymondos K, Scheinichen D, Koppert W, Rahe-Meyer N. Recovery of fibrinogen after administration of fibrinogen concentrate to patients with severe bleeding after cardiopulmonary bypass surgery. Br J Anaesth. 2010;104:555-62.

23. Rahe-Meyer N, Solomon C, Hanke A, Schmidt DS, Knoerzer D, Hochleitner G, Sorensen B, Hagl C, Pichlmaier M. Effects of fibrinogen concentrate as firstline therapy during major aortic replacement surgery: a randomized, placebo-controlled trial. Anesthesiology. 2013;118:40-50.

24. Manco-Johnson MJ, Dimichele D, Castaman G, Fremann S, Knaub S, Kalina U, Peyvandi F, Piseddu G, Mannucci P, Fibrinogen Concentrate Study G. Pharmacokinetics and safety of fibrinogen concentrate. J Thromb Haemost. 2009;7:2064-9.

25. Tanaka KA, Esper S, Bolliger D. Perioperative factor concentrate therapy. $\mathrm{Br} J$ Anaesth. 2013;111 Suppl 1:135-49.

26. Kintzel PE, Eastlund T, Calis KA. Extracorporeal removal of antimicrobials during plasmapheresis. J Clin Apher. 2003;18:194-205.

27. Kale-Pradhan PB, Woo MH. A review of the effects of plasmapheresis on drug clearance. Pharmacother. 1997;17:684-95.

28. Rosendale JD, Kauffman HM, McBride MA, Chabalewski FL, Zaroff JG, Garrity ER, Delmonico FL, Rosengard BR. Hormonal resuscitation yields more transplanted hearts, with improved early function. Transplantation. 2003;75:1336-41.
29. Tanaka KA, Bader SO, Sturgil EL. Diagnosis of perioperative coagulopathy - plasma versus whole blood testing. J Cardiothorac Vasc Anesth. 2013;27:S9-15.

\section{Submit your manuscript to a SpringerOpen ${ }^{\circ}$ journal and benefit from:}

- Convenient online submission

- Rigorous peer review

- Immediate publication on acceptance

- Open access: articles freely available online

- High visibility within the field

- Retaining the copyright to your article

Submit your next manuscript at springeropen.com 